\section{A) Check for updates}

Cite this: Food Funct., 2020, 11, 5887

\title{
Optimization of ergosterol extraction from Pleurotus mushrooms using response surface methodology
}

\author{
Oludemi Taofiq, (DD a Ana Rita Silva, ${ }^{a, b}$ Cristina Costa, (D) ${ }^{c}$ Inês Ferreira, ${ }^{c}$ João Nunes, ${ }^{c}$ \\ Miguel A. Prieto, Jesús Simal-Gandara, (D) ${ }^{d}$ Lillian Barros (D) ${ }^{* a}$ and \\ Isabel C. F. R. Ferreira (D) *a
}

\begin{abstract}
In this study, heat-assisted extraction (HAE) was used to maximize ergosterol extraction from Pleurotus ostreatus (PO) and Pleurotus eryngii (PE) using response surface methodology (RSM). Different temperature $(T)$ and time $(t)$ conditions were applied to understand their influence on the extraction yield $\left(Y_{1}\right)$, ergosterol purity in the extracted material $\left(\mathrm{mg} \mathrm{g}^{-1} \mathrm{R}, Y_{2}\right)$ and ergosterol content in the two Pleurotus species ( $\mathrm{mg}$ per $100 \mathrm{~g} \mathrm{dw}, Y_{3}$ ). A circumscribed central composite design was used to evaluate the interactive effects of extraction variables and the optimal conditions were determined using second-order polynomial mathematical models to describe the responses obtained. In all cases, the predicted responses showed satisfactory fitting between the predicted and experimental values $\left(R^{2}\right.$ values $\left.>0.8\right)$. The global optimum conditions predicted by the models were for $\mathrm{PO}$ at $T=54.3^{\circ} \mathrm{C}$ and $t=150 \mathrm{~min}$ (yielded 7.25\%, $33.32 \mathrm{mg} \mathrm{E}$ per $\mathrm{g} \mathrm{R}$ and $244.25 \mathrm{mg} \mathrm{E}$ per $100 \mathrm{~g} \mathrm{dw}$ ), while for $\mathrm{PE}$ at $T=61.8^{\circ} \mathrm{C}$ and $t=$ $150 \mathrm{~min}$ (yielded 8.02\%, $43.63 \mathrm{mg} \mathrm{E}$ per g R and $360.58 \mathrm{mg}$ E per $100 \mathrm{~g} \mathrm{dw}$ ). The obtained results from the two Pleurotus mushroom species using HAE show the possibilities of using them as a production source of enriched extracts in ergosterol.
\end{abstract}

Received 6th February 2020 Accepted 1st June 2020

DOI: $10.1039 / \mathrm{d} 0 f 000301 \mathrm{~h}$

rsc.li/food-function lated in the increase in commercial cultivation of several edible mushrooms. Numerous bioactive compounds, namely polysaccharides, peptides, glycoproteins, phenolics, sterols, lipids and hydrolytic and oxidative enzymes, have been extracted from crude extracts, mycelia, and basidiocarps of several mushroom species. ${ }^{7,8}$

The market for novel functional foods in the last decade has focused on bioactive metabolites (polyphenols, $\beta$-glucans, and fungal sterols) obtained from edible mushrooms displaying cholesterol lowering capacity. ${ }^{9,10}$ The mechanisms behind the cholesterol lowering capacity are not entirely clear but likely include multiple pathways that might disrupt cholesterol absorption. ${ }^{11}$ Ergosterol being structurally similar to cholesterol mainly displays hypocholesterolemic activity by impairing with cholesterol absorption, thereby displacing it from dietary mixed micelles (DMMs) formed during digestion. ${ }^{12}$ Some other steroidal compounds, mainly of plant origin (sitosterol, campesterol, and stigmasterol), also show cholesterol lowering capacity by inhibiting ACAT (acyl-CoA:cholesterol acyltransferase), a key enzyme involved in cellular cholesterol metabolism. ${ }^{11,12}$ An ergosterol derivative (Agarol) obtained from Agaricus blazei Murrill was reported to induce caspaseindependent apoptosis in human cancer cells, making it a promising ingredient for developing anticancer formu- 
lations. ${ }^{13}$ Several other therapeutic advancements, $\alpha$-glucosidase inhibitory capacity, ${ }^{14}$ leishmanicidal activity, ${ }^{15}$ and in vivo and in vitro anti-inflammatory activity, ${ }^{16}$ have been associated with ergosterol rich extracts and as such, more studies are now focused on the enhanced recovery of ergosterol from mushrooms for functional food development. ${ }^{17-19}$

Among several extraction techniques used to obtain ergosterol from mushrooms, the conventional extraction methods (maceration and heat-assisted extraction (HAE)) in their simplest form involve mixing mushrooms and the solvent of choice, allowing for interaction and subsequent release of bioactive compounds at certain time and a specific temperature. ${ }^{20}$ Independent of the employed extraction systems, extraction of target compounds is influenced by several variables that need to be analyzed jointly. Response surface methodology (RSM) is an effective tool for optimizing extraction processes, offering advantages of a reduced number of experimental trials and the ability to analyze multiple interactive effects among variables. $^{21,22}$ Hence, the present study aimed at optimizing the HAE process to extract ergosterol from Pleurotus eryngii (DC.) Quél., and Pleurotus ostreatus (Jacq. ex Fr.) P. Kumm. The combined effects of temperature $\left(T,{ }^{\circ} \mathrm{C}\right)$ and time $(t, \mathrm{~min})$ were analyzed by RSM aiming to find the optimum conditions that maximize ergosterol extraction.

\section{Materials and methods}

\subsection{Mushroom samples}

The fruiting bodies of $P$. eryngii (PE) and P. ostreatus (PO) mushroom species used in the present work were produced by solid state fermentation and cultivated by MicNatur (SME, Spin off of BLC3 - Oliveira do Hospital), on a controlled closed system. The samples were freeze-dried until constant weight (Telstar LyoQuest 85) and milled to a fine powder ( 40 mesh), and then mixed to form homogenate samples. The samples were then packed under vacuum and stored in laminated pouches.

\subsection{Standards and reagents}

HPLC grade methanol and acetonitrile were purchased from Fisher Scientific (Lisbon, Portugal). Ergosterol standard was purchased from Sigma (St Louis, MO, USA). Water was treated in a Milli-Q water purification system (TGI Pure Water Systems, Greenville, SC, USA). All other chemicals and solvents utilized in the present work were of analytical grade and purchased from common suppliers.

\subsection{Ergosterol extraction and quantification}

2.3.1. Heat-assisted extraction (HAE). Dry mushroom powder was extracted in a thermostatic water bath under continuous electro-magnetic stirring maintaining the solid/liquid ratio $(\mathrm{S} / \mathrm{L})$ at $30 \mathrm{~g} \mathrm{~L}^{-1}$. The extraction is carried out. Extraction was conducted using different $t$ and $T$ as defined by the RSM design: $t$ (10 to $150 \mathrm{~min}$ ) and $T\left(30\right.$ to $90^{\circ} \mathrm{C}$ ). After extraction, samples were filtered, the supernatant was carefully collected, and the dry weight was obtained to deduce the extraction yield.

2.3.2. Ergosterol characterization. Each dried mushroom extract was re-dissolved in ethanol and filtered through a $0.22 \mu \mathrm{m}$ nylon disposable filter. The ergosterol identification and quantification were performed in an integrated HPLC-UV system, composed of a pump (Knauer, Smartline system 1000, Berlin, Germany), a degasser system (Smartline manager 5000), an auto-sampler (AS-2057 Jasco, Easton, MD, USA), and a UV detector (Knauer Smartline 2500), using a procedure similar to that previously described by Barreira et al. ${ }^{23}$ The mobile phase was acetonitrile/methanol (70:30, v/v) and detection was performed at $280 \mathrm{~nm}$. Ergosterol was quantified using a calibration curve obtained from a commercial standard. Clarity 2.4 Software (DataApex) was employed for data analysis.

\subsection{Response surface methodology}

The RSM family designs are used for modeling and analysis of problems in which a response of interest is influenced by several variables. The RSM was used to optimize with the purpose of finding favorable conditions.

2.4.1. Response format values to present the results. The results were expressed in three response $(Y)$ format values: $Y_{1}$, the $\%$ of extracted material $(\mathrm{R}) ; Y_{2}$, in $\mathrm{mg}$ of ergosterol obtained in the extract residue ( $\mathrm{mg} \mathrm{E}$ per $\mathrm{g} \mathrm{R}$ ), which was specifically used to evaluate the ergosterol purity in the extracts; and $Y_{3}$, in $\mathrm{mg}$ of ergosterol in $100 \mathrm{~g}$ of mushroom dry weight material (mg E per $100 \mathrm{~g} \mathrm{M} \mathrm{dw}$ ), which was specifically used to analyze the ergosterol extraction yields.

2.4.2. Experimental design. Trials were conducted based on one-at-a-time analysis of each of the variables for each of the selected techniques. The variables that caused significant changes and the relevant ranges of action were selected for each one of the studied technique. The variables were coded according to the needs of the experimental design. The combined effect of these three variables was studied using a circumscribed central composite design (CCCD) using five levels for each one with 16 response combinations (three replicates per condition). Experimental runs were randomized, to minimize the effects of unexpected variability in the observed responses.

2.4.3. Mathematical model. Response surface models were fitted by means of least-squares calculation using the following second order polynomial equation:

$$
Y=b_{0}+\sum_{i=1}^{n} b_{i} X_{i}+\sum_{\substack{i=1 \\ j>i}}^{n-1} \sum_{j=2}^{n} b_{i j} X_{i} X_{j}+\sum_{i=1}^{n} b_{i i} X_{i}^{2}
$$

where $Y$ is the dependent variable (response variable) to be modeled, $X_{i}$ and $X_{j}$ define the independent variables, $b_{0}$ is the constant coefficient, $b_{i}$ is the coefficient of the linear effect, $b_{i j}$ is the coefficient of the interactive effect, $b_{i i}$ is the coefficient of the quadratic effect and $n$ is the number of variables.

2.4.4. Procedure to optimize the variables to a maximum response. A simplex method was used to optimize the predic- 
tive model by solving nonlinear problems in order to maximize the responses $\left(Y_{1}, Y_{2}\right.$ and $\left.Y_{3}\right)$ individually or globally. ${ }^{24}$ Certain limitations were imposed (i.e., $t$ lower than 0 ) to avoid variables with unnatural and unrealistic physical conditions.

\subsection{Numerical methods and statistical analysis}

Fitting procedures, coefficient estimation and statistical calculations were performed as previously described. ${ }^{24,25}$ In brief, (a) the coefficient measurement was carried out using the nonlinear least-squares (quasi-Newton) method provided by the macro "Solver" in Microsoft Excel, which allows minimizing the sum of the quadratic differences between the observed and model-predicted values and (b) the coefficient significance was evaluated using 'SolverAid' to determine the parametric confidence intervals. The not statistically significant terms ( $p$-value >0.05) were dropped to simplify the model and (c) the model reliability was verified using the following statistical assessment criteria: (i) the Fisher $F$-test $(\alpha=$ 0.05 ) was used to determine whether the constructed models were adequate to describe the observed data; (ii) the 'SolverStat' macro was used for the assessment of parameter and model prediction uncertainties; and (iii) $R^{2}$ was interpreted as the proportion of variability, of the dependent variable explained by the model.

\section{Results and discussion}

\subsection{Preliminary experimental data for all response criteria from CCCD}

The HAE involves mixing mushroom samples and ethanol, allowing interaction and subsequent release of bioactive compounds at specific time and temperature. It is an easy technique to scale up industrially, without the need for huge capital investment. Extraction of ergosterol has been achieved through homogenization in an appropriate solvent or through saponification of ergosterol esters using alcoholic $\mathrm{KOH}^{26}$ The latter process requires complex analytical conditions and may not be suitable for routine analysis. Hence, the employed HAE method proved to be a useful technique for rapidly determining the sterol profile using chromatographic methodologies and sample preparation protocols. Ethanol was selected as the solvent of choice because of its minimal environmental impact when compared to benzene, cyclohexane, and dichloromethane. More importantly, previous studies using the Soxhlet extraction system have shown that ethanol maximizes the extraction of ergosterol from Agaricus bisporus (J.E.Lange) Imbach (676 $\pm 3 \mathrm{mg}$ per $100 \mathrm{~g}$ $\mathrm{dw})$ when compared with limonene $(261 \pm 11 \mathrm{mg}$ per $100 \mathrm{~g}$ $\mathrm{dw})$ and $n$-hexane $(186.1 \pm 0.3 \mathrm{mg}$ per $100 \mathrm{~g} \mathrm{dw})$, while for ultrasound assisted extraction, ethanol has also shown better ergosterol yields (671 $\pm 5 \mathrm{mg}$ per $100 \mathrm{~g} \mathrm{dw}$ ), when compared with limonene $(372 \pm 0.1 \mathrm{mg}$ per $100 \mathrm{~g} \mathrm{dw})$ and $n$-hexane $(152.2 \pm 0.5 \mathrm{mg}$ per $100 \mathrm{~g} \mathrm{dw}) .{ }^{27}$

The circumscribed central composite design and the corresponding values obtained for each response criterion for the 16 treatments under the various experimental HAE conditions are shown in Table 1. The range of the experimental domains of the independent variables was selected based on the literature review and previous group experience attesting the efficiency of this method for ergosterol extraction. ${ }^{20}$

As shown in Table 1, in terms of PE, the highest extraction yield $\left({ }^{\mathrm{PE}} Y_{1}\right)$ of $15.79 \%$ was obtained for experimental run number 8, with operating conditions of $90{ }^{\circ} \mathrm{C}$ and $80 \mathrm{~min}$. For ${ }^{\mathrm{PE}} Y_{2}$, the highest ergosterol yield in $\mathrm{mg} \mathrm{E}$ per $\mathrm{g} \mathrm{R}$ was observed for experimental run number 9, when HAE was operating at $30{ }^{\circ} \mathrm{C}$ for $10 \mathrm{~min}$, while for ${ }^{\mathrm{PE}} Y_{3}$, the highest ergosterol yield in mg $\mathrm{E}$ per $100 \mathrm{~g} \mathrm{M}$ dw was observed for experimental run

Table 1 Experimental design and responses achieved. Variable values of the RSM experimental design applied in HAE are presented in coded and natural values. Extraction time $\left(X_{1}: t\right)$ and temperature $\left(X_{2}: T\right)$, combined in an experimental design of 12 independent variable combinations and 4 replicates at the centre of the experimental domain (16 data points)

\begin{tabular}{|c|c|c|c|c|c|c|c|c|c|c|}
\hline & \multicolumn{4}{|c|}{ Experimental variables } & \multicolumn{3}{|c|}{ Pleurotus eryngii (PE) } & \multicolumn{3}{|c|}{ Pleurotus osteratus (PO) } \\
\hline & $X_{1}$ & $(t, \min )$ & $X_{2}$ & $\left(T,{ }^{\circ} \mathrm{C}\right)$ & $Y_{1}$ & $Y_{2}$ & $Y_{3}$ & $Y_{1}$ & $Y_{2}$ & $Y_{3}$ \\
\hline 1 & -1 & $(30.5)$ & -1 & (38.8) & 5.85 & 42.03 & 245.73 & 5.15 & 48.13 & 247.73 \\
\hline 2 & -1 & $(30.5)$ & 1 & $(81.2)$ & 11.30 & 32.58 & 368.08 & 10.03 & 26.08 & 261.61 \\
\hline 3 & 1 & (129.5) & -1 & (38.8) & 6.13 & 57.63 & 353.22 & 5.67 & 12.55 & 71.21 \\
\hline 4 & 1 & (129.5) & 1 & $(81.2)$ & 13.02 & 25.60 & 333.27 & 7.79 & 29.43 & 229.24 \\
\hline 5 & -1.41 & (10) & 0 & $(60)$ & 8.11 & 39.88 & 323.36 & 5.35 & 41.43 & 221.58 \\
\hline 6 & 1.41 & $(150)$ & 0 & $(60)$ & 8.30 & 39.48 & 327.77 & 7.27 & 37.28 & 271.09 \\
\hline 7 & 0 & $(80)$ & -1.41 & (30) & 5.28 & 54.58 & 288.13 & 4.45 & 54.13 & 241.05 \\
\hline 8 & 0 & (80) & 1.41 & (90) & 15.79 & 16.75 & 264.52 & 3.34 & 29.33 & 98.08 \\
\hline 9 & -1.41 & (10) & -1.41 & (30) & 3.91 & 59.38 & 232.17 & 3.95 & 59.13 & 233.75 \\
\hline 10 & -1.41 & (10) & 1.41 & (90) & 8.45 & 37.30 & 315.14 & 9.65 & 30.45 & 293.91 \\
\hline 11 & 1.41 & (150) & -1.41 & (30) & 5.56 & 57.53 & 319.79 & 5.35 & 45.98 & 246.11 \\
\hline 12 & 1.41 & $(150)$ & 1.41 & (90) & 10.46 & 35.55 & 372.01 & 5.02 & 30.73 & 154.39 \\
\hline 13 & 0 & $(80)$ & 0 & $(60)$ & 8.77 & 38.83 & 340.45 & 6.85 & 39.40 & 270.06 \\
\hline 14 & 0 & (80) & 0 & (60) & 7.16 & 44.18 & 316.26 & 6.69 & 39.23 & 262.37 \\
\hline 15 & 0 & (80) & 0 & (60) & 9.65 & 38.98 & 376.15 & 7.04 & 35.63 & 250.91 \\
\hline 16 & 0 & $(80)$ & 0 & $(60)$ & 9.14 & 37.33 & 341.06 & 6.97 & 35.98 & 250.57 \\
\hline
\end{tabular}


number 12, with an extraction temperature of $90{ }^{\circ} \mathrm{C}$ and an extraction time of $150 \mathrm{~min}$. Regarding PO, the highest extraction yield $\left({ }^{\mathrm{PO}} Y_{1}\right)$ of $10.03 \%$ was obtained for experimental run number 2 , with an extraction temperature of $81.2^{\circ} \mathrm{C}$ and an extraction time of $30.5 \mathrm{~min}$. For ${ }^{{ }^{\mathrm{O}}} \mathrm{Y}_{2}$, the highest ergosterol yield in $\mathrm{mg} \mathrm{E}$ per $\mathrm{g} \mathrm{R}$ was observed for experimental run number 9, with $\mathrm{HAE}$ operating at $30^{\circ} \mathrm{C}$ and $10 \mathrm{~min}$, while for ${ }^{\mathrm{PO}} Y_{3}$, the ergosterol yield in $\mathrm{mg} \mathrm{E}$ per $100 \mathrm{~g} \mathrm{M} \mathrm{dw}$ was observed for experimental run number 10 with HAE operating at $90{ }^{\circ} \mathrm{C}$ and $10 \mathrm{~min}$. Also, ${ }^{\mathrm{PE}} Y_{2}$ presented the lowest response when $\mathrm{HAE}$ was operated at $90{ }^{\circ} \mathrm{C}$ and $80 \mathrm{~min}$, while ${ }^{\mathrm{PO}} Y_{2}$ and ${ }^{\mathrm{PO}} Y_{3}$ presented the lowest response when HAE was operated at $129.5 \mathrm{~min}$ and $38.8^{\circ} \mathrm{C}$, which showed that the influence of temperature was more significant in ${ }^{\mathrm{PE}} Y_{2}$. Comparatively, higher temperature is seen to favor higher extraction yield $\left(Y_{1}\right)$ in both mushroom samples and the lowest extraction yield in both cases was also observed in experimental runs with lower temperatures, while for $Y_{2}(\mathrm{mg}$ E per $g$ R), which is a measure of ergosterol purity in the extracts, lower temperature was found to present the highest yield. The results of this chromatographic quantification were used as response criteria to optimize the HAE conditions by RSM.

\subsection{Development of the theoretical response surface models}

As it is not advisable to extrapolate the individual or global optimum conditions that maximize extraction of bioactive compounds from the experimental responses, the secondorder polynomial equation will be utilized to make predictions unreliable. After fitting eqn (1) to the three possible responses $\left(Y_{1}, Y_{2}\right.$ and $\left.Y_{3}\right)$, the estimated parametric values, parametric intervals and numerical statistical criteria were obtained and are presented in Table 2. Those coefficients, which showed effects higher than the parameter value, were considered as non-significant (ns) and were not considered for the model development. The responses shown in Table 2 were correlated with the two independent variables using the polynomial equation. Consequently, non-linear equations were built based on the second-order polynomial model of eqn (1) and the best fit models in the coded factors are as follows:

For P. ostreatus

$$
\begin{gathered}
{ }^{\mathrm{PO}} Y_{1}=6.73-0.41 t+0.81 T+0.55 t^{2}-0.95 T^{2}-0.74 t T \\
{ }^{\mathrm{PO}} Y_{2}=37.42-3.23 t-6.40 T+3.29 t T \\
{ }^{\mathrm{PO}} Y_{3}=240.58-23.72 t-4.68 T+17.57 t^{2}-30.58 T^{2}-7.98 t T
\end{gathered}
$$

For P. eryngii

$$
\begin{gathered}
{ }^{\mathrm{PE}} Y_{1}=9.25+0.53 t+2.54 T-1.10 t^{2}+0.33 T^{2} \\
{ }^{\mathrm{PE}} Y_{2}=37.79-9.83 T+3.41 t^{2}-1.12 \mathrm{t} T \\
{ }^{\mathrm{PE}} Y_{3}=336.23+17.19 t+16.26 T-17.71 T^{2}-10.19 t T
\end{gathered}
$$

Fitting the models to the selected responses is crucial to elucidate how precisely the RSM mathematical model can predict ideal variances. These equations translate the patterns for each assessed mushroom extract and the corresponding responses: eqn (2)-(4) for $P$. ostreatus and eqn (5)-(7) for $P$. eryngii. Note that not all the parameters of eqn (1) were used for building the model since some coefficients were rejected (Table 2). Although parametric values obtained for each response showing the linear, interactive and quadratic effects are empirical, they can be utilized to predict the results of untested extraction conditions. The sign of the effect marks the response performance, and as such, when a factor has a positive effect, the response is higher at a high level. Similarly, when a factor has a negative effect, the response is lower at a high level, meaning the higher the absolute value of a coefficient, the more vital the weight of the corresponding variable. The developed response models also showed similar trends for both mushrooms, with both presenting a combination of linear, interactive and quadratic coefficients for all three responses.

Regarding the interactive effects for the HAE system in terms of ${ }^{{ }^{\mathrm{O}}} Y_{1}$, a negative interaction was observed between $t$ and $T$, while for the linear effect, the effect was positive for $T$

Table 2 Parametric results of the second-order polynomial equation of eqn (1) for the analysis of the response value formats $\left(Y_{1}\right.$, yield in \%; $Y_{2}$, mg E per g R; and $Y_{3} \mathrm{mg} \mathrm{E}$ per $100 \mathrm{~g} \mathrm{M} \mathrm{dw}$ ) of Pleurotus eryngii and Pleurotus ostreatus mushroom species. Analysis of significance of the parameters ( $\alpha$ $=0.05$ ) is presented in coded values. Additionally, the statistical information of the fitting procedure to the model is presented

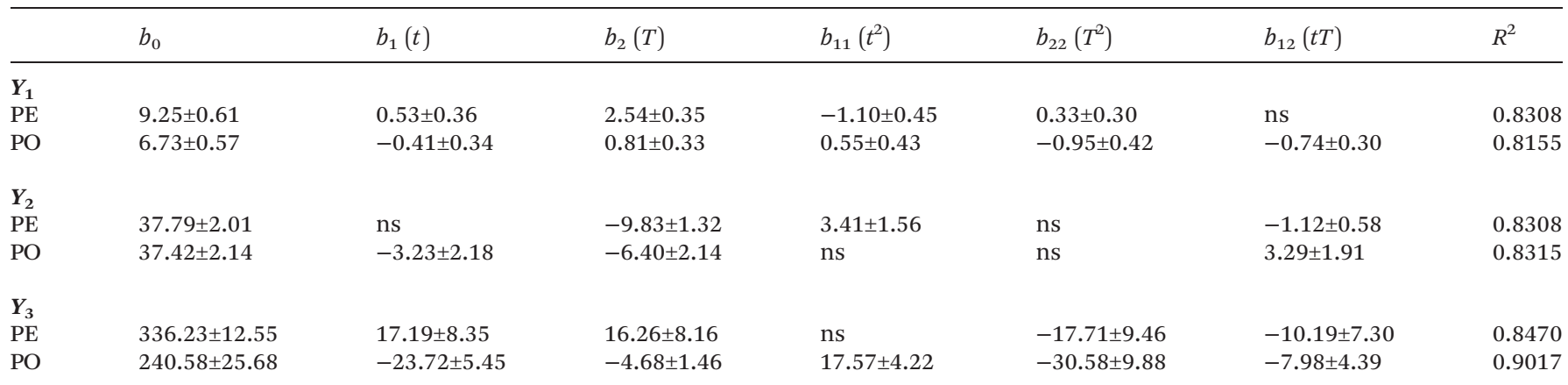

ns: non-significant coefficient; $R^{2}$ : correlation coefficient. 
and negative for $t$. This suggests that temperature improved the extraction yield of $P$. ostreatus. In the case of ${ }^{\mathrm{PE}} Y_{1}$, the linear effect of both $T$ and $t$ had positive values, which indicate that the extraction yield increases with higher extraction time and higher temperature, while the interactive effect of $t$ and $T$ was found to be non-significant. Regarding ${ }^{\mathrm{PO}} Y_{2}$, it is possible to observe a positive interactive effect between both variables, while the linear effect is negative for both $t$ and $T$. This indicates that higher $t$ and $T$ might be beneficial to improve exudation of active biomolecules from the ruptured cell walls, but prolonged exposure (longer extraction time and higher temperature) may cause increased extraction of compounds that are not of interest and subsequent deterioration of ergosterol purity in the extract. In terms of ${ }^{\mathrm{PE}} Y_{2}$, the interactive term of $t$ and $T$ was insignificant, while a positive linear effect was found for both $t$ and $T$. In terms of ${ }^{\mathrm{PO}} Y_{3}$, extraction time and temperature had both significant positive and negative quadratic effects, respectively, while the linear effect of $t$ and $T$ was significant and negative in both cases. In summary, for ${ }^{\mathrm{PO}} Y_{3}$, almost all significant terms (linear, quadratic and interactive effects) showed negative effects. Conversely, with respect to ${ }^{\mathrm{PE}} Y_{3}$, the patterns show that the variable $t$ and $T$ ratio changes the response to a larger extent than the interactive effect between both independent variables. These patterns are opposite to the ones found in ${ }^{\mathrm{PE}} Y_{3}$.

In terms of the statistical analysis of the fitting of the models to the responses, the quadratic regression model for both mushroom samples resulted in determination of the $R^{2}$ coefficient. This parameter measures how well the suggested model fit the experimental data, and the closer the value of $R^{2}$ is to 1 , the better is the correlation between the measured and the predicted values. As shown in Table $2, R^{2}$ values for all three responses in both $\mathrm{PO}$ and PE showed values greater than 0.8 , which implies that the corresponding model term is highly significant, and more than $80 \%$ variability was successfully explained by the proposed model. The obtained results indicate that the developed mathematical model has the potential to describe ergosterol obtainment using heat assisted extraction very robustly.

The profile patterns derived from the parametric values of these mathematical models on the assessed response criteria can also be depicted by graphical representation. These figures presented in the form of response surface plots and contour plots were obtained based on the model equation. They show the interaction among variables and determine the optimal level of each factor for maximum ergosterol yield in both mushrooms. Fig. 1A and B show the graphical profile patterns derived from the parametric values of these mathematical models in terms of response value $Y_{1}(\%)$ and $Y_{2}$ (mg E per g R) for P. ostreatus and P. eryngii. In subsection A, points $(\bullet)$ represent the obtained experimental results (Table 1) and the net surface represents the theoretical 3D response surface predicted with the second order polynomial eqn (1) as a function of each of the variables involved. Twodimensional contour plots representing the fitting results of eqn (1) are shown in subsection B. The statistical description is illustrated in subsection $\mathrm{C}$ and in this case, two basic graphical criteria are used: a plot showing the ability to simulate the changes of the response (i.e. predicted values versus the observed experimental values) and the residual distribution (i.e. difference between the experimental and the predicted value) as a function of each of the considered variables. In subsection $\mathrm{D}$, the dots $(\odot)$ presented alongside each line highlight the location of the optimum value. The binary actions between variables are presented when the excluded variable is positioned at the optimum of the experimental domain.

The properly optimized responses for both PE and PO $\left(Y_{1}\right.$, $\left.Y_{2}, Y_{3}\right)$ display patterns in which the quantity of extractable biomolecules increases to an optimum value and then decreases as a function of each of the assessed independent variables. For PE, the interactive effect of temperature and time was not significant for all three responses, but both factors demonstrated quadratic effects on the response ${ }^{\mathrm{PE}} Y_{2}$. This shows that the extraction time caused a linear increase in the response ${ }^{\mathrm{PE}} Y_{2}$ at low levels of temperature. In addition, ${ }^{\mathrm{PE}} Y_{1}$ and ${ }^{\mathrm{PE}} Y_{3}$ showed similar trends, with temperature displaying a quadratic effect in both responses. Therefore, in almost all combinations, the optimum can be found at one single point along with the response, allowing for determination of the optimum conditions that lead to the absolute maximum. Visual analysis of contour plots (Fig. 1A and B, subsection B) was consistent with the experimental values of ${ }^{\mathrm{PE}} Y_{2}$ and ${ }^{\mathrm{PO}} Y_{2}$, obtained under different HAE conditions presented in Table 1. It was noticeable that the temperature dominantly influences the responses compared to the extraction time.

Also, the adequacy of the developed mathematical model to represent the HAE process for both PE and PO was evaluated by constructing a diagnostic residual plot representing the difference between predicted and experimental values. The residual plots are anticipated to follow a normal distribution if the experimental errors were arbitrary. From the graphical representations (Fig. 1A and B, subsection C) which show the data points, it can be seen that they lie very close to the diagonal line and as such, depict a good relationship between experimental values and those predicted by the proposed model. From these results, it is concluded that the developed mathematical model can describe the HAE process for obtaining an ergosterol rich extract very robustly and can be utilized for future scale-up.

A general summary of the patterns of ergosterol extraction efficiency for the three response formats is also shown in Fig. 2. Regarding the particular case of PO, the intense influence of temperature observed in ${ }^{\mathrm{PO}} Y_{3}$ dictates its action: when raising the temperature until $60^{\circ} \mathrm{C}$ the ergosterol content also increases (above $250 \mathrm{mg}$ per $100 \mathrm{~g} \mathrm{dw}$ ), followed afterward by a decrease in this content. In the case of ${ }^{\mathrm{PE}} Y_{2}$, the short extraction time coupled with low temperature needed to maximize the response is very suitable for industrial applications, considering that minimal cost will be needed in terms of energy consumption. Besides being an enhanced optimum in terms 
Figure 1A - Extraction Yield

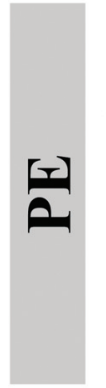

\section{A: JOIN ACTION (3D)}
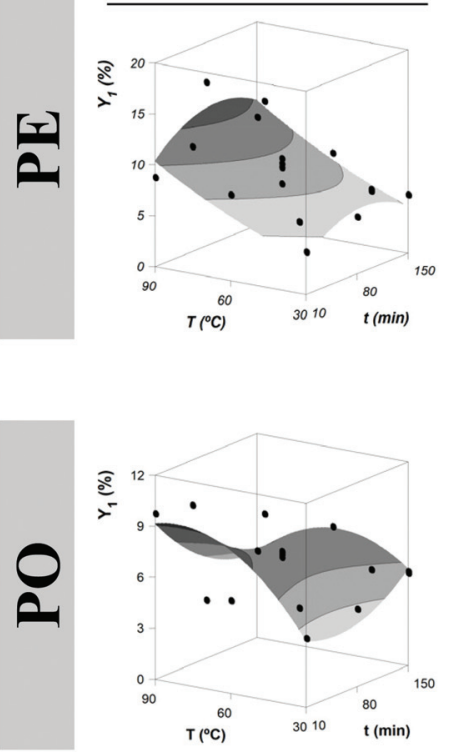
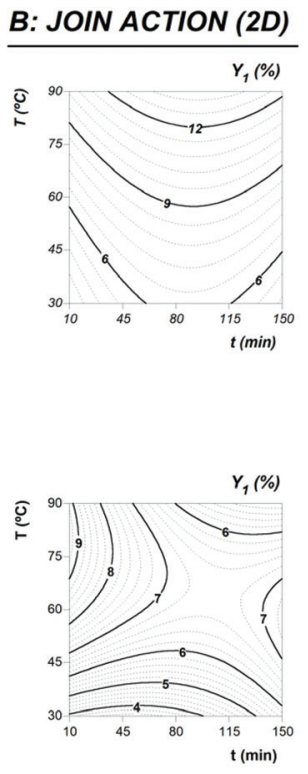

C: STATISTICAL ANALYSIS

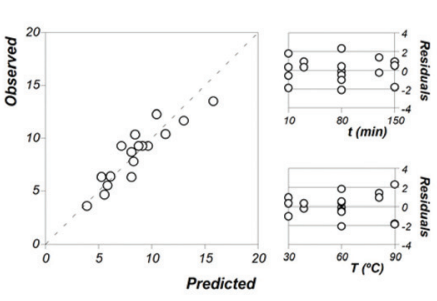

\section{D: OPTIMAL VALUES}
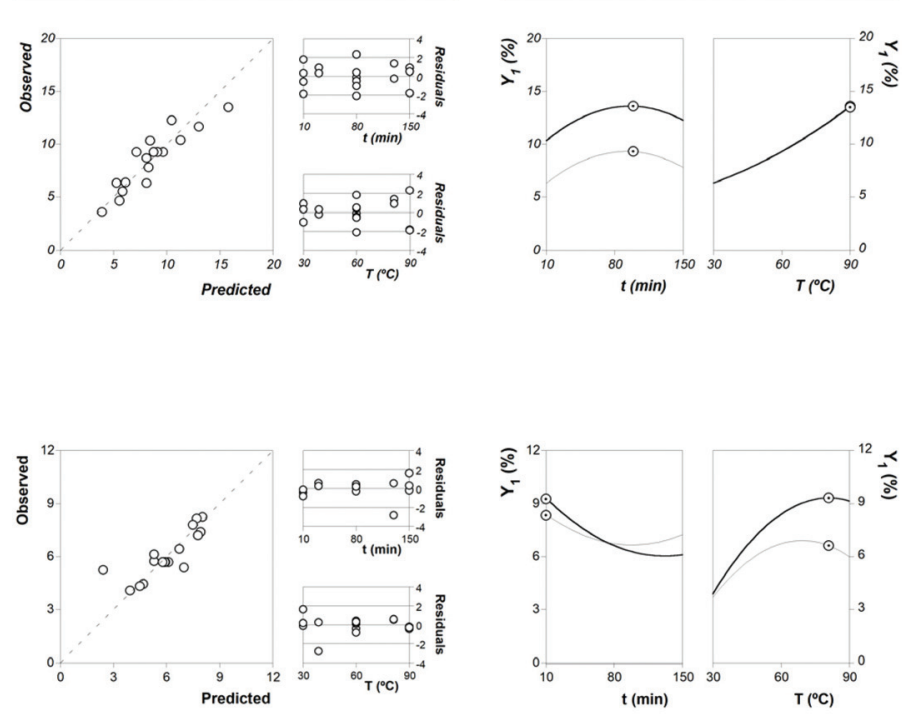

Figure 1B - Ergosterol content

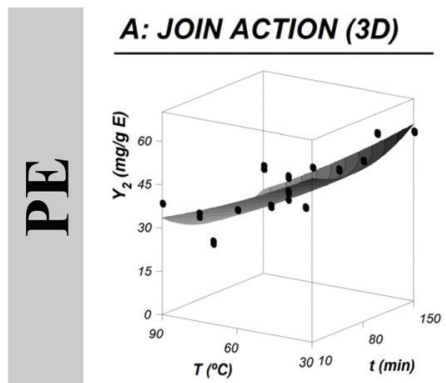

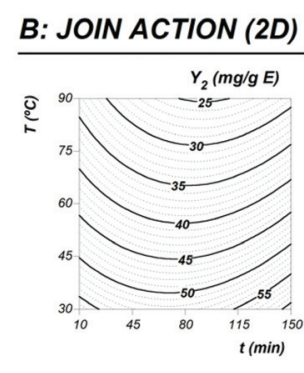

C: STATISTICAL ANALYSIS
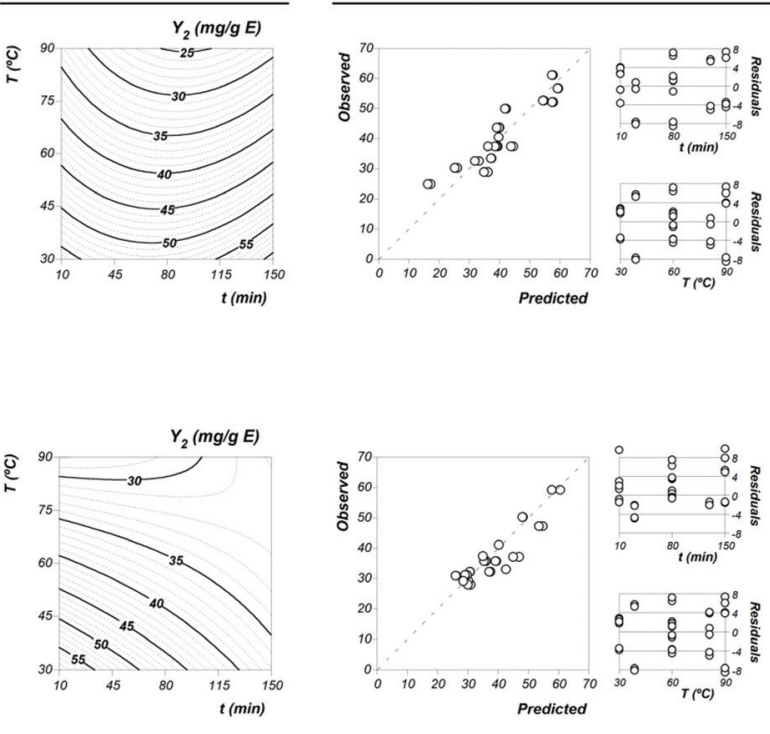

\section{D: OPTIMAL VALUES}
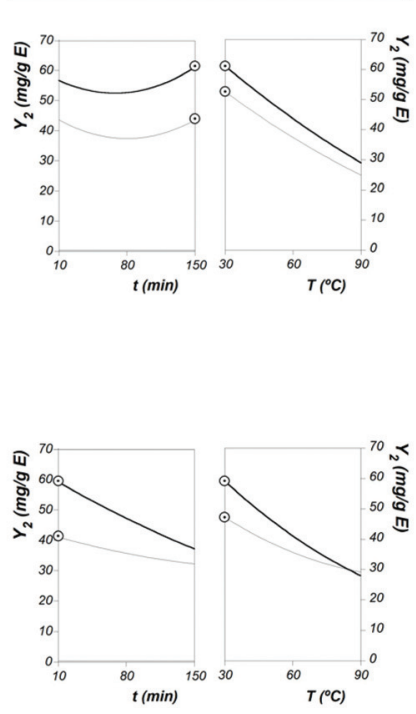

Fig. 1 (A and B) Graphical profile patterns derived from the parametric values of these mathematical models in terms of response value $Y_{1}$ (\%) and $Y_{2}$ (mg E per g R). Subsection A: Points $(\bullet)$ represent the obtained experimental results (Table 1 ) and the net surface represents the theoretical 3D response surface predicted with the second order polynomial eqn (1) as a function of each of the variables involved. Estimated parametric values of are shown in Table 2. Subsection B: Two-dimensional representation of the fitting results of eqn (1). The binary actions between variables are presented when the excluded variable is positioned at the optimum of the experimental domain (Table 3). Subsection C: To illustrate the statistical description, two basic graphical criteria are used: the ability to simulate the changes of the response and the residual distribution as a function of each of the variables. Subsection D: The dots $(\odot)$ presented alongside each line highlight the location of the optimum value.

of yield, the optimum for ${ }^{\mathrm{PE}} Y_{2}$ and ${ }^{{ }^{\mathrm{O}}} Y_{2}$ is also economical optimum. The arrows displayed in Fig. 2 show that to obtain a ${ }^{\mathrm{PE}} Y_{3}$ optimal response, high to moderate temperatures $\left(\sim 60^{\circ} \mathrm{C}\right)$ and high extraction time presented the optimal solu- tion. These results, together with the linear parametric values of the second-order polynomial equation for time and temperature, show the negative impact of time and minor influence of high temperature on ${ }^{\mathrm{PE}} Y_{3}$ response. 

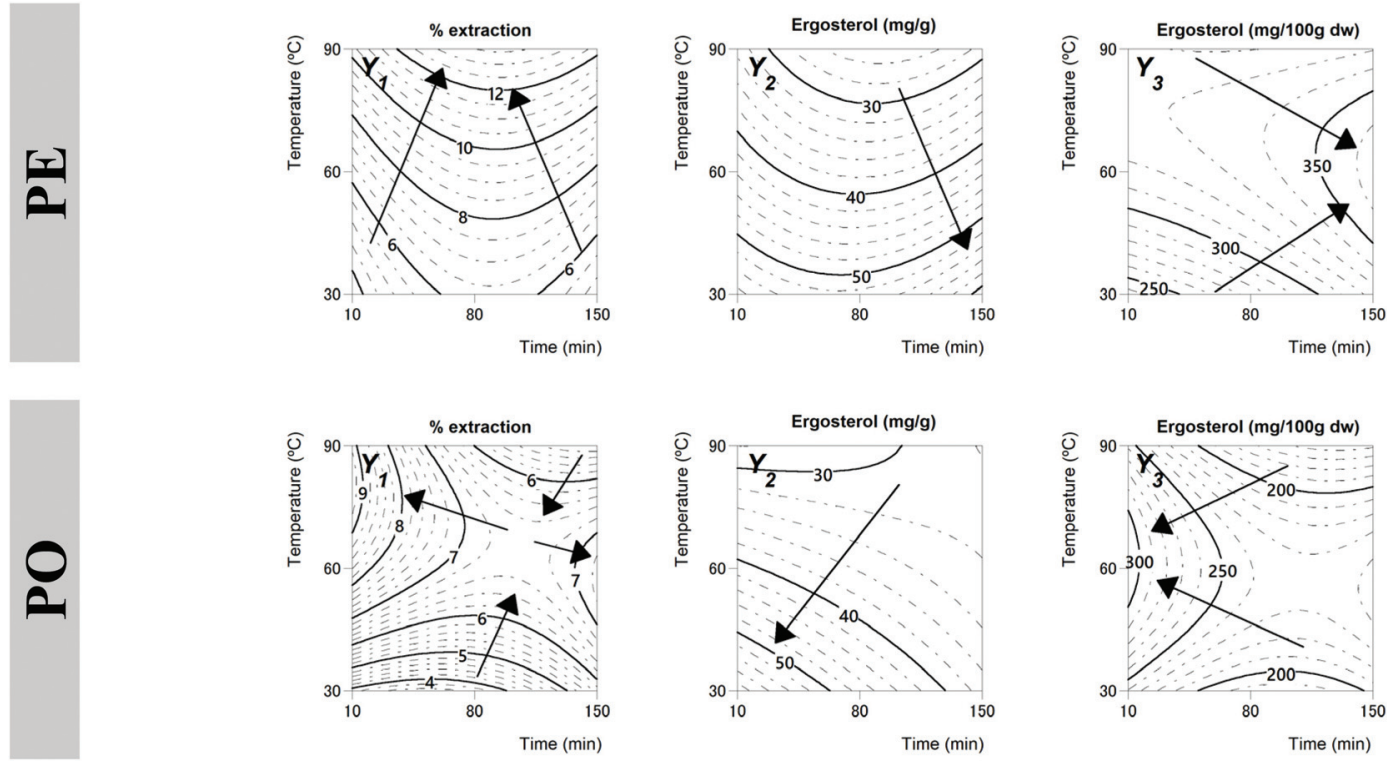

Fig. 2 Graphical summary of the RSM results for the optimization of the two main variables involved $\left(X_{1}\right.$ and $\left.X_{2}\right)$ in the extraction of ergosterol from Pleurotus eryngii and Pleurotus ostreatus mushroom species for the three response value formats assessed $\left(Y_{1}\right.$, yield in \%; $Y_{2}$, mg E per g R; and $Y_{3}$ mg E per $100 \mathrm{~g} \mathrm{M} \mathrm{dw).}$

\subsection{The optimum conditions of HAE process experimental verification of predictive models}

By applying a simplex method to solve nonlinear problems, the optimum individual conditions maximizing the recovery of ergosterol were determined for the three possible response format values. In addition, the global optimum conditions can also be determined. Both individual and global optimal conditions are presented in Table 3. Comparing both mushrooms, and regarding the individual optimum conditions predicted by the model:

Table 3 Variable conditions in natural values that lead to optimal response values for RSM for the three individual response value formats $\left(Y_{1}\right.$, yield in \%; $Y_{2}$, mg E per $\mathrm{g} \mathrm{R}$; and $Y_{3} \mathrm{mg} E$ per $100 \mathrm{~g} \mathrm{M} \mathrm{dw}$ ) and for the global optimal conditions

Optimum variable

conditions

Criteria $\quad X_{1}: t(\min ) \quad X_{2}: T\left({ }^{\circ} \mathrm{C}\right) \quad$ Optimum response

\begin{tabular}{lllll}
\hline \multicolumn{4}{l}{ (A) Individual optimum conditions } \\
$\mathrm{PE}$ & $Y_{1}$ & 91.9 & 90.0 & $13.56 \%$ \\
& $Y_{2}$ & 150.0 & 30.0 & $60.75 \mathrm{mg} \mathrm{E}$ per $\mathrm{g} \mathrm{R}$ \\
& $Y_{3}$ & 150.0 & 61.1 & $360.60 \mathrm{mg}$ E per $100 \mathrm{~g} \mathrm{M} \mathrm{dw}$ \\
$\mathrm{PO}$ & $Y_{1}$ & 10.0 & 80.9 & $9.32 \%$ \\
& $Y_{2}$ & 10.0 & 30.0 & $57.61 \mathrm{mg} \mathrm{E}$ per $\mathrm{g} \mathrm{R}$ \\
& $Y_{3}$ & 150.0 & 61.0 & $246.31 \mathrm{mg}$ E per $100 \mathrm{~g} \mathrm{M} \mathrm{dw}$
\end{tabular}

(B) Global optimal conditions

$\begin{array}{lllll}\mathrm{PE} & Y_{1} & 150 & 61.8 & 8.02 \% \\ & Y_{2} & & & 43.63 \mathrm{mg} \mathrm{E} \text { per } \mathrm{g} \mathrm{R} \\ & Y_{3} & & & 360.58 \mathrm{mg} \text { E per } 100 \mathrm{~g} \mathrm{M} \mathrm{dw} \\ \mathrm{PO} & Y_{1} & 150 & 54.3 & 7.25 \% \\ & Y_{2} & & & 33.32 \mathrm{mg} \mathrm{E} \text { per } \mathrm{g} \mathrm{R} \\ & Y_{3} & & & 244.25 \mathrm{mg} \text { E per } 100 \mathrm{~g} \mathrm{M} \mathrm{dw}\end{array}$

- For the extraction yield, ${ }^{\mathrm{PE}} Y_{1}$ response was the best solution (13.56\%), at $91.9 \mathrm{~min}$ and $90{ }^{\circ} \mathrm{C}$.

- For ergosterol purity in the extract, ${ }^{\mathrm{PE}} Y_{2}$ response was the best solution (60.75 $\mathrm{mg}$ E per $\mathrm{g} \mathrm{R}$ ) at $150 \mathrm{~min}$ and $30{ }^{\circ} \mathrm{C}$.

- For the response value ${ }^{\mathrm{PE}} Y_{3}, 360.60 \mathrm{mg}$ E per $100 \mathrm{~g}$ dw was achieved at $150 \mathrm{~min}$ and $61.1^{\circ} \mathrm{C}$.

- For the extraction yield, in the case of ${ }^{{ }^{P O}} Y_{1}$, the best solution was obtained $(9.32 \%)$ at $10 \mathrm{~min}$ and $80.9{ }^{\circ} \mathrm{C}$.

- For the ergosterol purity in the extract, ${ }^{{ }^{P O}} Y_{2}, 57.61 \mathrm{mg}$ Eper $\mathrm{g}^{-1} \mathrm{R}$, was achieved when HAE was operating at $10 \mathrm{~min}$ and $30^{\circ} \mathrm{C}$.

- For the response value ${ }^{\mathrm{PO}} Y_{3}, 246.31 \mathrm{mg}$ E per $100 \mathrm{~g}$ dw was achieved at $150 \mathrm{~min}$ and $61^{\circ} \mathrm{C}$.

Regarding the global optimum conditions predicted by the model: for PO, $54.3{ }^{\circ} \mathrm{C}$ and $150 \mathrm{~min}$ yielded $7.25 \%, 33.32 \mathrm{mg} \mathrm{E}$ per $\mathrm{g} \mathrm{R}$ and $244.25 \mathrm{mg} \mathrm{E}$ per $100 \mathrm{~g} \mathrm{dw}$ for the responses $Y_{1}, Y_{2}$ and $Y_{3}$, respectively, while for PE, $61.8{ }^{\circ} \mathrm{C}$ and $150 \mathrm{~min}$ yielded 8.02\%, $43.63 \mathrm{mg} \mathrm{E}$ per $\mathrm{g} \mathrm{R}$ and $360.58 \mathrm{mg} \mathrm{E}$ per $100 \mathrm{~g} \mathrm{dw}$ for the responses $Y_{1}, Y_{2}$, and $Y_{3}$, respectively. The main advantages of innovative techniques such as UAE and MAE procedures are lower extraction time and a relatively higher yield. In terms of ${ }^{\mathrm{PO}} Y_{2}$ which was performed in only $10 \mathrm{~min}$ and at $30^{\circ} \mathrm{C}$ (consuming less energy and time) high ergosterol purity in the extract was achieved, which is aligned with the requirements of a green technology. Hence some of the optimal conditions that favor enhanced ergosterol yield can be considered as an important tool to increase efficiency with minimal energy and cost function. With new changes occurring worldwide to ensure sustainable development, most biobased processes are suffering significant transformation to achieve better extraction process efficiencies and reduce its environmental impact. ${ }^{28-30}$ Further studies will be conducted to examine the 
effect of the solid-liquid (S/L) ratio and in order to investigate this effect, experiments will be performed under the optimum conditions predicted by the model using several S/L variations. Small values of the S/L ratio often lead to a more effective dissolution, causing an extraction yield enhancement, but also a waste of solvent. ${ }^{31}$ Hence, S/L ratios between 10 and $120 \mathrm{~g} \mathrm{~L}^{-1}$ will be selected as the suitable range to be further studied using RSM analysis.

\subsection{Comparison of HAE and other extraction methods}

The qualitative and quantitative studies of bioactive compound extraction from natural matrices mostly rely on the selection of appropriate extraction methods, the range of the experimental conditions and the understanding of the dynamic chemical nature of various bioactive molecules present in these natural matrices. ${ }^{32}$ Extraction using nonconventional methods (UAE, MAE, SFE) is more environmentally friendly due to the decreased use of synthetic and organic chemicals, reduced extraction time, and higher extraction yield. At the same time, conventional extraction methods, such as Soxhlet and HAE, are still considered reference methods to compare the success of the newly developed methodologies. Ergosterol has been extracted successfully from different mushroom extracts ${ }^{18,27,31,33}$ and some previous reports dealing with the optimization of ergosterol extraction from different mushrooms are presented in Table 4. Each mushroom material has compositional diversity and as such, the tested conditions for ergosterol extraction cannot be directly extrapolated for each other. Analyzing the findings in Table 4, A. bisporus and other edible or medicinal mushrooms belonging to the Agaricus genus are seen to be the most widely reported sources of ergosterol. Most of the methods reported in Table 4 were carried using one variable at a time, which in most cases does not guarantee enhanced extraction. Hence, carrying out RSM using a series of experimental domains, and a possible combination of independent variables, presents advantages. To the best of our knowledge, very few studies are available on ergosterol recovery from $P$. eryngii with Souilem et al. (2017) reporting a low yield from its fruiting body $\left(4.1 \pm 0.3 \mathrm{mg} \mathrm{g}^{-1}\right)$ and mycelium $\left(0.6 \pm 0.1 \mathrm{mg} \mathrm{g}^{-1}\right)$. In contrast, $78.20 \pm 0.54 \mathrm{mg} \mathrm{g}^{-1}$ was recovered from $P$. ostreatus Soxhlet ethanolic extract. Comparing ergosterol yield from Pleurotus and Agaricus genus using non-saponification extraction methodologies,

Table 4 Bibliographic summary of ergosterol content from some common edible mushrooms using different extraction techniques and conditions

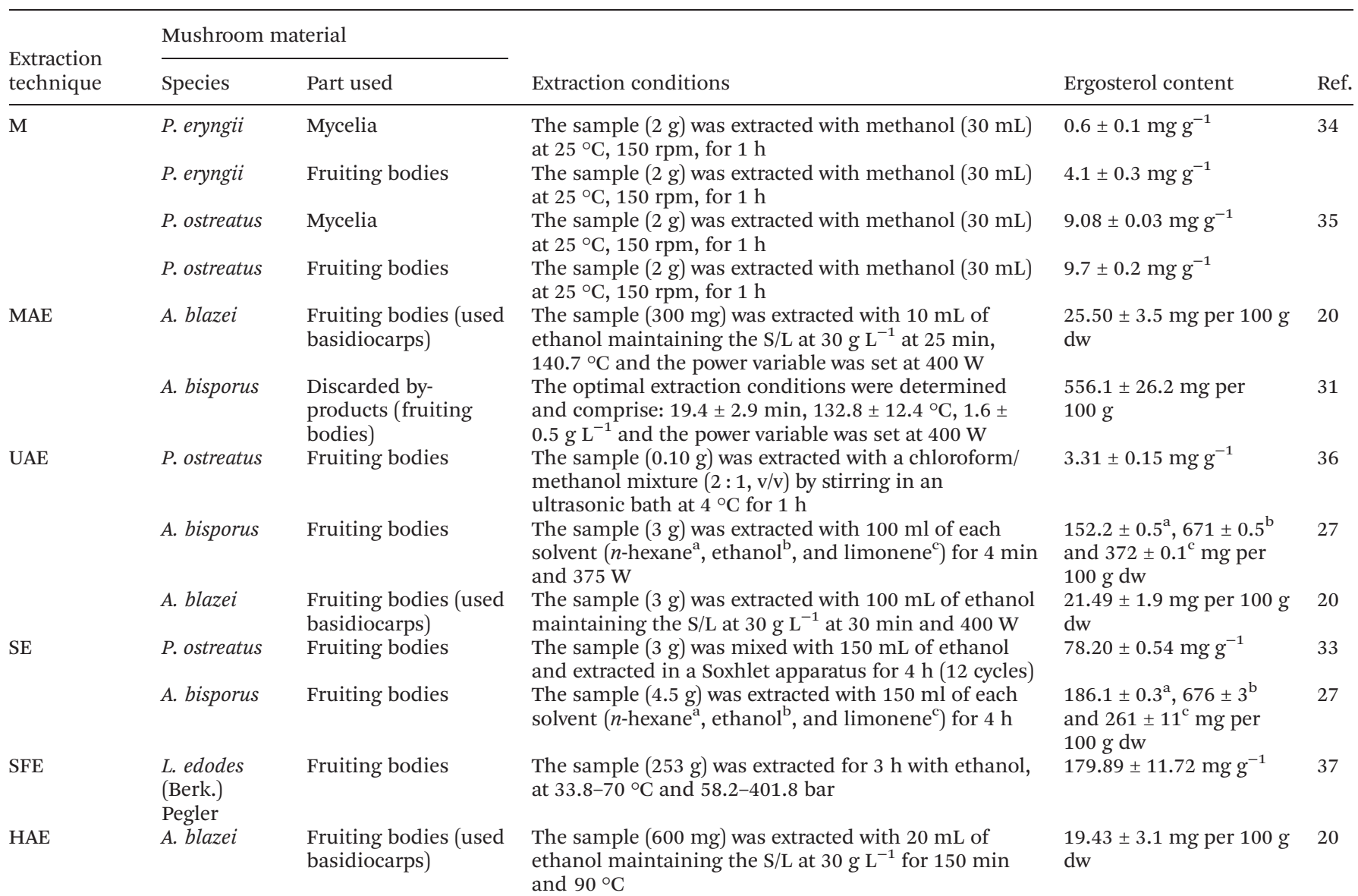

HAE: heat assisted extraction; M: maceration; MAE: microwave assisted extraction; UAE: ultrasound assisted extraction; SE: Soxhlet extraction; SFE: supercritical fluid extraction. 
the highest yield reported so far is for the UAE and MAE systems both for A. bisporus. ${ }^{27,31}$ Considering that both MAE and UAE above were conducted in lab-based extractors, huge capital investments will be needed to further develop them into industrial extractors with high loading capacity. Hence, the HAE system employed in the present work can be an attractive option towards enhancing ergosterol yield from Pleurotus mushrooms considering minimal costs for operational setup.

\section{Conclusions}

Response surface methodology (RSM) was utilized to determine the influence of extraction parameters as well as predict optimum conditions that maximize the recovery of ergosterol from $P$. eryngii and $P$. ostreatus mushrooms. Mathematical modelling of the extraction process was carried out by circumscribed central composite design (CCCD) and based on preliminary experiments, temperature $\left(30-90{ }^{\circ} \mathrm{C}\right)$ and time (10-150 $\mathrm{min})$ were selected as two independent variables. Predicting abilities of mathematical models were investigated by $3 \mathrm{D}$ and $2 \mathrm{D}$ response surface plots and optimal extraction conditions were determined as follows: $\mathrm{PO}, 54.3{ }^{\circ} \mathrm{C}$ and 150 min yielded $7.25 \%, 33.32 \mathrm{mg}$ E per $\mathrm{g} \mathrm{R}$ and $244.25 \mathrm{mg} \mathrm{E}$ per $100 \mathrm{~g} \mathrm{dw}$ for the responses $Y_{1}, Y_{2}$, and $Y_{3}$ respectively, while for PE, $61.8{ }^{\circ} \mathrm{C}$ and $150 \mathrm{~min}$ yielded $8.02 \%, 43.63 \mathrm{mg} \mathrm{E}$ per $\mathrm{g} \mathrm{R}$ and $360.58 \mathrm{mg} \mathrm{E}$ per $100 \mathrm{~g} \mathrm{dw}$ for the responses $Y_{1}, Y_{2}$, and $Y_{3}$ respectively. This research offers evidence that HAE is still an effective technique for the extraction of ergosterol from mushrooms using moderate to high temperatures and different time intervals. Considering the surplus amount of fruiting bodies that are discarded in the mushroom production/processing chain, these results presented herein can be an initial stage towards their valorization at the industrial level.

\section{Conflicts of interest}

The authors declare no conflict of interest, financial or otherwise.

\section{Acknowledgements}

The authors are grateful to the Foundation for Science and Technology (FCT, Portugal) for financial support through national funds FCT/MCTES to CIMO (UIDB/00690/2020); this work was also funded by the European Agricultural Fund for Rural Development (EAFRD), through the Rural Development Program (PDR2020), within the scope of the project MicoCoating (PDR2020-101-03147). L. Barros also acknowledges the national funding by FCT, P.I., through the institutional scientific employment program-contract for their contracts. MICINN is acknowledged for the financial support for the Ramón\&Cajal researcher, M.A. Prieto.

\section{References}

1 D. Sande, G. P. de Oliveira, M. A. F. Moura, B. de Almeida Martins, M. T. N. S. Lima and J. A. Takahashi, Edible mushrooms as a ubiquitous source of essential fatty acids, Food Res. Int., 2019, 108524.

2 O. Taofiq, A. M. González-Paramás, A. Martins, M. F. Barreiro and I. C. F. R. Ferreira, Mushrooms extracts and compounds in cosmetics, cosmeceuticals and nutricosmetics-A review, Ind. Crops Prod., 2016, 90, 38-48.

3 S. A. Heleno, A. Martins, M. J. R. P. Queiroz and I. C. F. R. Ferreira, Bioactivity of phenolic acids: Metabolites versus parent compounds: A review, Food Chem., 2015, 173, 501-513.

4 L. Barros, T. Cruz, P. Baptista, L. M. Estevinho and I. C. F. R. Ferreira, Wild and commercial mushrooms as source of nutrients and nutraceuticals, Food Chem. Toxicol., 2008, 46, 2742-2747.

5 Â. Fernandes, A. L. Antonio, J. C. M. Barreira, M. B. P. P. Oliveira, A. Martins and I. C. F. R. Ferreira, Effects of gamma irradiation on physical parameters of Lactarius deliciosus wild edible mushrooms, Postharvest Biol. Technol., 2012, 74, 79-84.

6 M. E. Valverde, T. Hernández-pérez and O. Paredes-lópez, Edible mushrooms: improving human health and promoting quality life, Int. J. Microbiol, 2015, 376387.

7 N. K. Lee and B.-Y. Aan, Optimization of ergosterol to vitamin $\mathrm{D}_{2}$ synthesis in Agaricus bisporus powder using ultraviolet-B radiation, Food Sci. Biotechnol., 2016, 25, 1627-1631.

8 T. C. Finimundy, L. Barros, R. C. Calhelha, M. J. Alves, M. A. Prieto, R. M. V. Abreu, A. J. P. Dillon, J. A. P. Henriques, M. Roesch-Ely and I. C. F. R. Ferreira, Multifunctions of Pleurotus sajor-caju (Fr.) Singer: A highly nutritious food and a source for bioactive compounds, Food Chem., 2018, 245, 150-158.

9 R. C. G. Corrêa, R. M. Peralta, A. Bracht and I. C. F. R. Ferreira, The emerging use of mycosterols in food industry along with the current trend of extended use of bioactive phytosterols, Trends Food Sci. Technol., 2017, 67, 19-35.

10 F. S. Reis, A. Martins, M. H. Vasconcelos, P. Morales and I. C. F. R. Ferreira, Functional foods based on extracts or compounds derived from mushrooms, Trends Food Sci. Technol., 2017, 66, 48-62.

11 E. D. Jesch and T. P. Carr, Food ingredients that inhibit cholesterol absorption, Prev. Nutr. Food Sci., 2017, 22, 6780.

12 A. Gil-Ramírez, L. Aldars-García, M. Palanisamy, R. M. Jiverdeanu, A. Ruiz-Rodríguez, F. R. Marín, G. Reglero and C. Soler-Rivas, Sterol enriched fractions obtained from Agaricus bisporus fruiting bodies and byproducts by compressed fluid technologies (PLE and SFE), Innovative Food Sci. Emerging Technol., 2013, 18, 101-107.

13 T. Shimizu, J. Kawai, K. Ouchi, H. Kikuchi, Y. Osima and R. Hidemi, Agarol, an ergosterol derivative from Agaricus 
blazei, induces caspase-independent apoptosis in human cancer cells, Int. J. Oncol., 2016, 48, 1670-1678.

14 S. Chen, T. Yong, C. Xiao, J. Su, Y. Zhang, C. Jiao and Y. Xie, Pyrrole alkaloids and ergosterols from Grifola frondosa exert anti- $\alpha$-glucosidase and anti-proliferative activities, J. Funct. Foods, 2018, 43, 196-205.

15 D. G. Valadares, M. C. Duarte, J. S. Oliveira, M. A. ChávezFumagalli, V. T. Martins, L. E. Costa, J. P. V. Leite, M. M. Santoro, W. C. B. Régis, C. A. P. Tavares and E. A. F. Coelho, Leishmanicidal activity of the Agaricus blazei Murill in different Leishmania species, Parasitol. Int. , 2011, 60, 357-363.

16 N. Fangkrathok, J. Junlatat and B. Sripanidkulchai, In vivo and in vitro anti-inflammatory activity of Lentinus polychrous extract, J. Ethnopharmacol., 2013, 147, 631-637.

17 R. Corrêa, L. Barros, A. Fernandes, M. Sokovic, A. Brachtc, R. M. Peralta and I. C. F. R. Ferreira, A natural food ingredient based on ergosterol: optimization of the extraction from Agaricus blazei, evaluation of bioactive properties and incorporation in yogurts, Food Funct., 2018, 14651474.

18 C. R. L. Francisco, S. A. Heleno, I. P. M. Fernandes, J. C. M. Barreira, R. C. Calhelha, L. Barros, O. H. Gonçalves, I. C. F. R. Ferreira and M. F. Barreiro, Functionalization of yogurts with Agaricus bisporus extracts encapsulated in spray-dried maltodextrin crosslinked with citric acid, Food Chem., 2018, 245, 845-853.

19 S. A. Heleno, A. R. Rudke, R. C. Calhelha, M. Carocho, L. Barros, O. H. Gonçalves, M. F. Barreiro and I. C. F. R. Ferreira, Development of dairy beverages functionalized with pure ergosterol and mycosterol extracts: an alternative to phytosterol-based beverages, Food Funct., 2017, 8, 103-110.

20 O. Taofiq, R. C. G. Corrêa, L. Barros, M. A. Prieto, A. Bracht, R. M. Peralta, A. M. González-paramás, M. F. Barreiro and I. C. F. R. Ferreira, A comparative study between conventional and non-conventional extraction techniques for the recovery of ergosterol from Agaricus blazei Murrill, Food Res. Int., 2019, 125, 108541.

21 T. Oludemi, L. Barros, M. A. Prieto, S. A. Heleno, M. F. Barreiro and I. C. F. R. Ferreira, Extraction of triterpenoids and phenolic compounds from Ganoderma lucidum: optimization study using the response surface methodology, Food Funct., 2018, 9, 209-226.

22 Z. Zhu, Q. Guan, M. Koubaa, F. J. Barba, S. Roohinejad, G. Cravotto, X. Yang, S. Li and J. He, HPLC-DAD-ESI-MS2 analytical profile of extracts obtained from purple sweet potato after green ultrasound-assisted extraction, Food Chem., 2017, 215, 391-400.

23 J. C. M. Barreira, M. B. P. P. Oliveira and I. C. F. R. Ferreira, Development of a Novel Methodology for the Analysis of Ergosterol in Mushrooms, Food Anal. Methods, 2014, 7, 217-223.

24 V. Vieira, M. A. Prieto, L. Barros, J. A. P. Coutinho, O. Ferreira and I. C. F. R. Ferreira, Optimization and comparison of maceration and microwave extraction systems for the production of phenolic compounds from Juglans regia L. for the valorization of walnut leaves, Ind. Crops Prod., 2017, 107, 341-352.

25 J. Pinela, M. A. Prieto, M. F. Barreiro, A. M. Carvalho, M. B. P. P. Oliveira, J. A. Vázquez and I. C. F. R. Ferreira, Optimization of microwave-assisted extraction of hydrophilic and lipophilic antioxidants from a surplus tomato crop by response surface methodology, Food Bioprod. Process., 2016, 98, 283-298.

26 J. C. M. Barreira, S. Rodrigues, A. M. Carvalho and I. C. F. R. Ferreira, Development of hydrosoluble gels with Crataegus monogyna extracts for topical application: Evaluation of antioxidant activity of the final formulations, Ind. Crops Prod., 2013, 42, 175-180.

27 S. A. Heleno, P. Diz, M. A. Prieto, L. Barros, A. Rodrigues, M. F. Barreiro and I. C. F. R. Ferreira, Optimization of ultrasound-assisted extraction to obtain mycosterols from Agaricus bisporus L. by response surface methodology and comparison with conventional Soxhlet extraction, Food Chem., 2016, 197, 1054-1063.

28 I. Ait Amer Meziane, N. Maizi, N. Abatzoglou and E. H. Benyoussef, Modelling and optimization of energy consumption in essential oil extraction processes, Food Bioprod. Process., 2020, 119, 373-389.

29 C. J. López, C. Caleja, M. A. Prieto, M. F. Barreiro, L. Barros and I. C. F. R. Ferreira, Optimization and comparison of heat and ultrasound assisted extraction techniques to obtain anthocyanin compounds from Arbutus unedo L. Fruits, Food Chem., 2018, 264, 81-91.

30 J. Pinela, M. A. Prieto, A. L. Antonio, A. M. Carvalho, M. B. P. P. Oliveira, L. Barros and I. C. F. R. Ferreira, Ellagitannin-rich bioactive extracts of Tuberaria lignosa: Insights into the radiation-induced effects in the recovery of high added-value compounds, Food Funct., 2017, 8, 2485-2499.

31 S. A. Heleno, M. A. Prieto, L. Barros, A. Rodrigues, M. F. Barreiro and I. C. F. R. Ferreira, Optimization of microwave-assisted extraction of ergosterol from Agaricus bisporus L. by-products using response surface methodology, Food Bioprod. Process., 2016, 100, 25-35.

32 J. Azmir, I. S. M. Zaidul, M. M. Rahman, K. M. Sharif, A. Mohamed, F. Sahena, M. H. A. Jahurul, K. Ghafoor, N. A. N. Norulaini and A. K. M. Omar, Techniques for extraction of bioactive compounds from plant materials: A review, J. Food Eng., 2013, 117, 426-436.

33 O. Taofiq, S. Heleno, R. Calhelha, M. Alves, L. Barros, M. Barreiro, A. González-Paramás and I. Ferreira, Development of Mushroom-Based Cosmeceutical Formulations with Anti-Inflammatory, Anti-Tyrosinase, Antioxidant, and Antibacterial Properties, Molecules, 2016, 21, 1372.

34 F. Souilem, Â. Fernandes, R. C. Calhelha, J. C. M. Barreira, L. Barros, F. Skhiri, A. Martins and I. C. F. R. Ferreira, Wild mushrooms and their mycelia as sources of bioactive compounds: Antioxidant, anti-inflammatory and cytotoxic properties, Food Chem., 2017, 230, 40-48. 
35 R. V. C. Cardoso, Â. Fernandes, M. B. P. P. Oliveira, R. C. Calhelha, L. Barros, A. Martins and I. C. F. R. Ferreira, Development of nutraceutical formulations based on the mycelium of Pleurotus ostreatus and Agaricus bisporus, Food Funct., 2017, 8, 2155-2164.

36 A. Villares, L. Mateo-Vivaracho, A. García-Lafuente and E. Guillamón, Storage temperature and UV-irradiation influence on the ergosterol content in edible mushrooms, Food Chem., 2014, 147, 252-256.

37 D. Morales, A. Gil-Ramirez, F. R. Smiderle, A. J. Piris, A. Ruiz-Rodriguez and C. Soler-Rivas, Vitamin D-enriched extracts obtained from shiitake mushrooms (Lentinula edodes) by supercritical fluid extraction and UV-irradiation, Innovative Food Sci. Emerging Technol., 2017, 41, 330-336. 